\title{
ALCÁZAR DE SAN JUAN Y SU HISTORIA DOCUMENTAL: ESTUDIO DE UNA PROVISIÓN REAL DE LA CHANCILLERÍA DE GRANADA (1573)
}

\author{
Juan Carlos Galende Díaz* \\ Universidad Complutense de Madrid \\ Nicolás Ávila Seoane** \\ Universidad Complutense de Madrid
}

\begin{abstract}
RESUMEN
Estudio de una provisión otorgada en 1573 por Felipe II durante el pleito que mantuvo la villa de Alcázar de San Juan contra la de Villafranca de los Caballeros y Pedro de Úbeda sobre la jurisdicción de las dehesas de Villacentenos y El Acebrón. Tras una breve introducción histórica y unas consideraciones generales sobre la tipología documental en cuestión, se llevan a cabo los correspondientes análisis de escritura y formulario diplomático empleados. Al final, la transcripción paleográfica del documento.
\end{abstract}

PALABRAS CLAVE: Paleografía, Diplomática, Felipe II, Alcázar de San Juan, provisión real 


\title{
ALCÁZAR DE SAN JUAN AND ITS DOCUMENTARY HISTORY: STUDY OF A ROYAL WRIT ISSUED BY THE CHANCELLERY OF GRANADA (1573)
}

\author{
Juan Carlos Galende Díaz* \\ Universidad COMPlutense DE MAdRid \\ Nicolás Ávila Seoane** \\ Universidad Complutense de Madrid
}

\begin{abstract}
Study of a writ issued in 1573 by Philip II during the lawsuit that kept the town of Alcázar de San Juan against Pedro de Ubeda and other individuals, regarding the meadows of Villacentenos and El Acebrón. After a brief historical introduction and some general considerations on the document type in question, we carry out the analysis of the writing and the diplomatic form that were used. Finally, we offer the paleographic transcription of the document.
\end{abstract}

KEYWORDS: Palaeography, Diplomatics, Philip II of Spain, Alcázar de San Juan, royal writ

*jgalende@ucm.es

**niavila@ucm.es 
Las dehesas de Villacentenos y El Acebrón, situadas en los alrededores de Alcázar de San Juan, que motivan la provisión que vamos a estudiar, arrastran una larga historia de pleitos entre concejos, particulares y el Honrado Concejo de la Mesta.

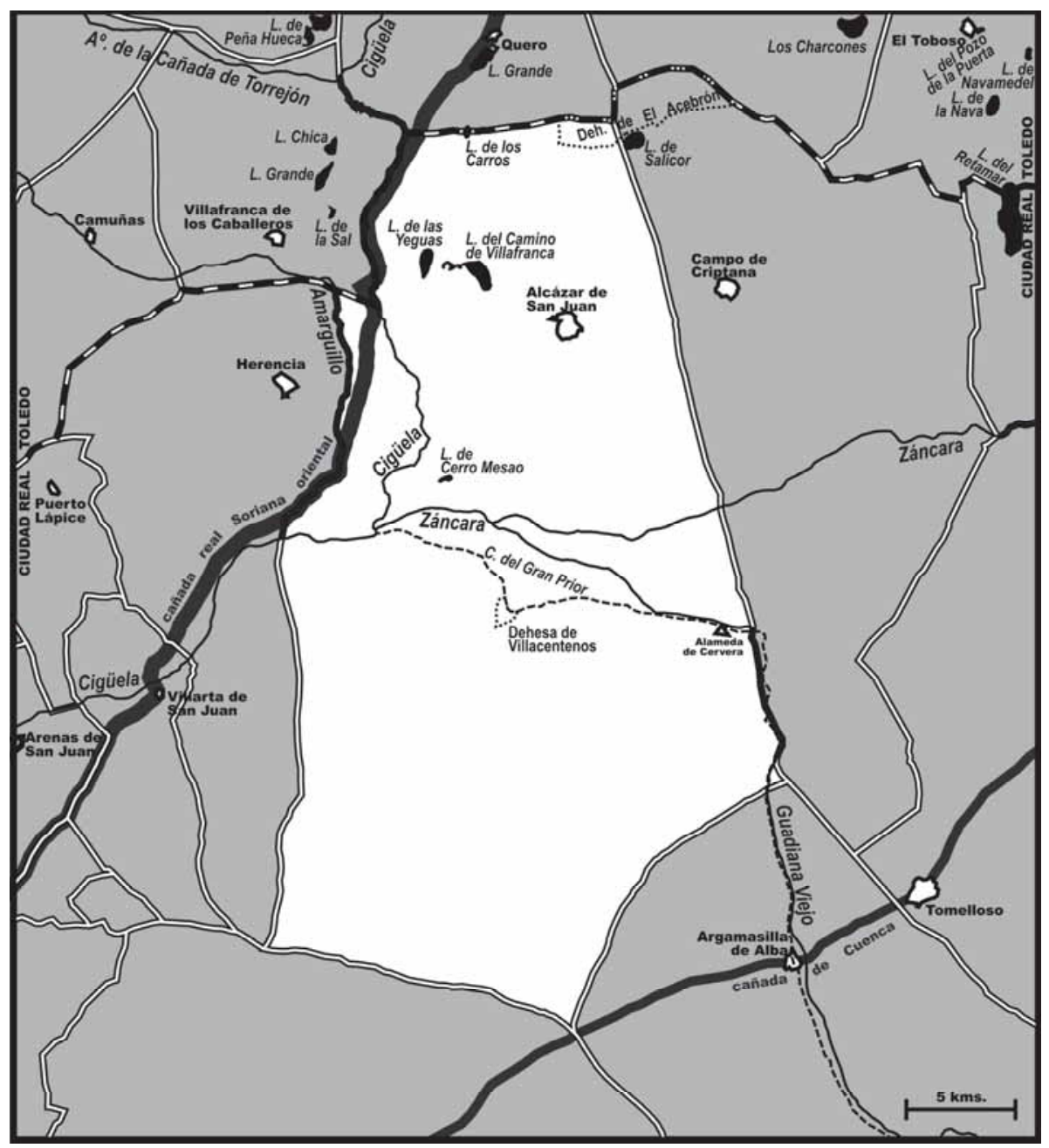

Imagen 1. Mapa del término municipal de Alcázar de San Juan y sus alrededores.

No se señalan ni Arenales de San Gregorio ni las pedanías de Cinco Casas,

Herrera de la Mancha y Llanos del Caudillo, por datar de la Edad Contemporánea.

Tras la batalla de Las Navas (1212), Alfonso VIII cedió a la orden de San Juan los castillos de Villacentenos, Peñarroya y Ruidera, merced 
confirmada en 1215 por Enrique I ${ }^{1}$. El 16 de abril de 1239 el comendador de Consuegra Ruy Pérez otorgó carta puebla a Herencia; los beneficios inherentes atrajeron a muchos pobladores del cercano lugar de Villacentenos ${ }^{2}$. Dos años después recibió también Alcázar carta puebla, que le asignaba "parte de Villacentenos"3. En 1292 otro comendador, Fernán Pérez, dio a Alcázar categoría de villa bajo la obligación de asentar en Villacentenos cincuenta vecinos ${ }^{4}$. A pesar de ello, el lugar fue poco a poco menguando hasta despoblarse; reducido a dehesa, un capítulo de la orden celebrado en 1457 lo cedió a censo perpetuo a Juan López Caballero ${ }^{5}$. Entre 1520 y 1529 su nieto Jerónimo de Ayllón pleiteó con el concejo de Alcázar sobre la jurisdicción de Villacentenos ${ }^{6}$, y en esos papeles se basa el cervantista Ángel Ligero Móstoles para aventurar que Alonso de Ayllón, hijo de Jerónimo, inspiró a Cervantes el personaje de don Quijote?

En 1563 el Honrado Concejo de la Mesta denunció a las villas de Alcázar, Villarta, Arenas y Herencia por impedir el paso de "ganados mayores e menores por el término que dizen de Villaçentenos" y haber tomado prendas

1. C. de Ayala Martínez (1995), 399-400; M. de los Á. Rodríguez Domenech (2008), 348; F. J. Atienza Santiago (2011), 14; P. Serrano De Menchén (2015), 166.

2. El documento original se ha perdido pero quedan diversas copias. Aquí partimos de la manuscrita de D. DE Aguirre (1769), 93-94. Sobre la carta puebla pueden consultarse M. Fernández-Montes y Corrales (1989), 21-24; Á. Martín-Fontecha Guijarro y J. Romero NúÑez (1996), 32; C. Barquero GoÑ (1997), 76.

3. V. M. López-Menchero Bendicho, Á. Marchante Ortega, G. Esteban Borrajo y M. Á. Hervás Herrera (2015), 14. El aprovechamiento de los recursos forestales de este enclave, en particular la bellota, provocó largos pleitos (A. DE Alces (2012), 5; M. Fernández-Montes y Corrales (2014), 82-87), como el seguido en 1618 por el gobernador del priorato de San Juan Alonso Leandro de Herrera contra los regidores de Herencia "sobre talas en los montes del Arenal y Açebrón, y coger bellota fuera de tiempo en la dehesa de Villacentenos". Archivo de la Real Chancillería de Granada (ARChG), caja 2710, pieza 20.

4. C. Barquero GoÑi (1997), 96-97. El privilegio de villazgo fue aprobado por Sancho IV ese mismo año y ratificado por Fernando IV en 1300, siendo esta última confirmación el texto más antiguo del Archivo Municipal de Alcázar de San Juan (AMASJ) (J. F. Sánchez Ruiz y F. J. Atienza Santiago (2011), 4-5 y 8).

5. F. J. Atienza Santiago (2011), 15, citando un documento del Archivo General de Palacio, Infante don Gabriel, anexo, leg. 1, núm. 28; V. M. López-Menchero Bendicho, Á. Marchante Ortega, G. Esteban Borrajo y M. Á. Hervás Herrera (2015), 16.

6. F. J. Atienza Santiago (2011), 15.

7. Á. Ligero Móstoles (1991), I, 159-188; F. Íñiguez Barrena (2007), 248. En el ARChG, caja 560, pieza 7, se conserva un "pleito entre el concejo de Alcázar con Jerónimo Ayllón, contador del priorazgo de San Juan, y otros, sobre una dehesa de Villacenteno", si bien Ángel Ligero declara haber consultado otra copia del AMASJ. 
de mesteños. De este proceso se conservan tres ejecutorias de Felipe II en favor del Concejo: una el 10 de diciembre de 1568, y las otras dos del 31 de enero de $1573^{8}$, mismo año de la provisión que aquí estudiamos, despachada con motivo de un pleito de Alcázar con Villafranca de los Caballeros sobre la jurisdicción de Villacentenos. Un siglo más tarde volvieron a litigar por el mismo motivo Alcázar y Herencia contra Arenas y Villarta; hay del proceso más de trescientos folios en la sección Consejos del Archivo Histórico Nacional, fechados entre 1668 y 1673, sin fallo definitivo9.

Bastante menos información existe sobre la dehesa de El Acebrón, situada en el extremo nordeste del término de Alcázar y que se extendía también por el vecino de Campo de Criptana, señorío ya de la orden de Santiago. Su aprovechamiento forestal, igual que el de Villacentenos, fue regulado mediante una ordenanza que aprobó el concejo en 1573 y ratificó Felipe II al año siguiente ${ }^{10}$. En 1603 las rentas de ambas dehesas quedaron vinculadas al pago de un préstamo que había tomado Alcázar del comisario de la Inquisición Fernando Díaz Guerrero ${ }^{11}$.

\section{SOBRE LAS PROVISIONES REALES}

Aparecen en la primera mitad del siglo XIV, emanadas del mandato o precepto, para transmitir órdenes a funcionarios o corporaciones. A partir de Juan I pueden suscribirlas, en vez del rey, diferentes instituciones implicadas aunque siempre bajo la intitulación regia ${ }^{12}$.

Perduran hasta el siglo XVII ${ }^{13}$ y representan el documento real por excelencia de la época moderna por la amplitud de temas que pueden abarcar: concesión de mercedes, nombramientos, otorgamiento de ordenanzas, resolución de pleitos, transmisión de órdenes... ${ }^{14}$, y no hay otro más solemne entre la documentación indiana ${ }^{15}$.

8. Archivo Histórico Nacional (AHN), Diversos-Concejo de la Mesta, leg. 11, docs. 14, 15 y 16. El pleito completo está en el ARChG, caja 2447, pieza 1.

9. AHN, Consejos, leg. 25996, exp. 2. Se aportan unas breves referencias a este pleito en J. MuÑoz Torres (2013), 5-7.

10. J. Muñoz Torres (2013), 11, 21, 24.

11. Á. Ligero Móstoles (1994), II, 199.

12. M. S. Martín Postigo (1959), 115-117; M. J. Sanz Fuentes (1981), 251-253; A. Tamayo LóPez-Machuca (1996), 138.

13. P. L. Lorenzo Cadarso (2001), 46-48.

14. Á. Hernández García (2001), 170-179.

15. J. J. Real Díaz (1970), 184.

(C) Baetica. Estudios Historia Moderna y Contemporánea, 38, 2018, 9-28. Facultad de Filosofía y Letras, Universidad de Málaga. Departamento de Historia Moderna y Contemporánea 
Al igual que en otros tipos diplomáticos, como la cédula, las provisiones pueden ser de oficio, despachadas por iniciativa del rey u organismo delegado, o bien a petición de parte en procedimientos incoados por particulares ${ }^{16}$.

Se expiden en papel y el texto forma un solo cuerpo compacto, redactado en la escritura cursiva acorde a la época: precortesana, cortesana o humanística cursiva. El formulario diplomático se estructura en invocación simbólica, intitulación, dirección, salutación, notificación, exposición, disposición, cláusulas sancionativas y corroborativas, data y una validación compuesta, además del sello céreo placado -bien en la parte inferior del recto, bien al dorso-, por las suscripciones autógrafas de los intervinientes en su conscriptio (visador, chanciller, registrador o escribano) y, hasta el siglo XV, la del propio rey que, a partir de entonces, se va sustituyendo por las de miembros de los diferentes órganos de gobierno que se iban creando: Consejo Real, otros consejos (Hermandad, Órdenes militares...), Chancillerías, Audiencias, Santo Oficio de la Inquisición...

El instrumento analizado aquí lo despachó la Chancillería de Granada el 4 de julio de $1573^{17}$. Mediante él Felipe II ordenaba sacar traslado de diferentes "probisiones y hordenanças e confirmaçiones" sobre Villacentenos y El Acebrón, que la villa de Alcázar requería para el pleito pendiente sobre la jurisdicción de estas dehesas, contra Villafranca de los Caballeros y Pedro de Úbeda ${ }^{18}$. Estamos en el mismo año en que, como vimos al principio, el rey había dado dos ejecutorias en favor del Concejo de la Mesta garantizando el libre tránsito de ganados por Villacentenos. En el catálogo de pleitos de la Chancillería no hay referencia al que aquí nos interesa $^{19}$, por lo que ignoramos el origen de la disputa; probablemente

16. Es de consulta obligada el clásico estudio de F. Arribas Arranz (1959), 11-44.

17. Se conserva en el AMASJ, caja 204, doc. 9, a cuyo archivero don Francisco José Atienza Santiago agradecemos las facilidades ofrecidas para su consulta y otras aclaraciones. Para conocer con detalle su labor de organización desde 2007 puede consultarse el artículo de F. J. Atienza Santiago y J. M. Mendoza Marín (2011), 269-299. También nos ha sido muy útil la recopilación historiográfica que él mismo ha elaborado junto con J. F. SÁnchez Ruiz, titulada Bibliografía de Alcázar de San Juan y cuyo primer volumen se publicó en 2014 .

18. Esta provisión formó parte de la exposición Alcázar en sus documentos hasta finales del siglo XVI, celebrada en enero y febrero de 2011. El Catálogo elaborado para aquella ocasión, junto a la data y el regesto, la describe así: "Manuscrito en papel, $435 \mathrm{x}$ 310 milímetros, humanística cursiva. Tintas metaloácidas sobre papel verjurado”. J. F. Sánchez Ruiz y F. J. Atienza Santiago (2011), 12.

19. http://www.juntadeandalucia.es/cultura/pleitos/buscador.htm (consultado el 17 de junio de 2016). 
respondiera a una denuncia por invadir el ganado las dehesas, o por talas ilícitas.

Se escrituró en la parte superior de un bifolio de papel, con brevete, sello y suscripciones al dorso. Su estado de conservación es en general bueno, pues la pérdida de un pequeño fragmento no afecta a la lectura.

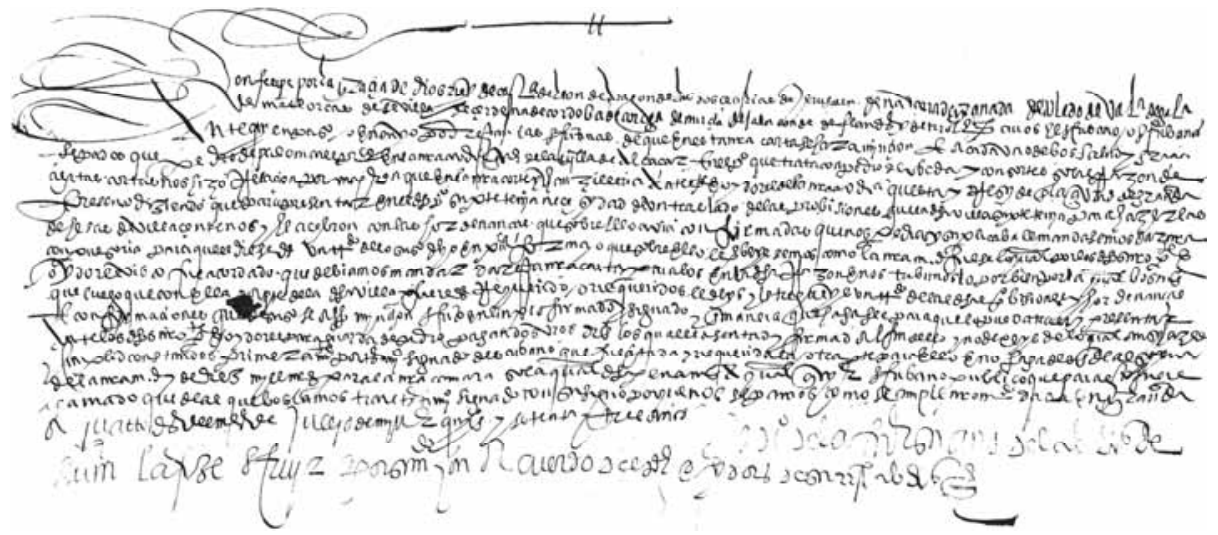

Imagen 2. Provisión de Felipe II del 4 de julio de 1573 (AMASJ, caja 204, doc. 9).

\section{COMENTARIO PALEOGRÁFICO}

La mano principal del texto y el brevete rasgueaba una humanística cursiva en su variedad corriente ${ }^{20}$, de trazado rápido y descuidada caligrafía, lo que se advierte, por ejemplo, en la imperfecta separación de palabras. Se mantienen reminiscencias góticas (en particular el empleo de alguna $a$ de corchete, la $d$ uncial volteada y la persistencia de $r$ recta en el nexo $t r$ ). Los enlaces son abundantes, al contrario que los nexos. Las abreviaturas, como veremos después, tampoco menudean.

El alfabeto ofrece las siguientes características:

20. Sobre la humanística, cuyos orígenes están ligados a la figura de Petrarca, pueden consultarse los siguientes estudios: G. Battelli (1954), 35-44; B. L. Ullman (1960); J. Wardrop (1963); M. L. Mandingorra Llavata (1986); A. J. Fairbank y R. W. Hunt (1993); J. C. Galende Díaz (1998), 187-230; E. Ruiz García (1999), 149-176; S. Zamponi (2004), 467-504; I. Ruiz Albi (2011), 47-71, y (2016), 217-236; A. TAmayo LÓPEZ-MACHUCA (2012), 445-454. 
a: casi siempre es redonda y de un solo trazo. Surge alguna gotizante, en forma de corchete. La mayúscula es uncial y de mayor módulo, con el capelo muy prolongado.

\section{a a $a$ a $n \quad r$}

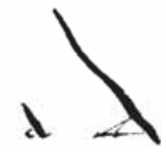

b: tanto el bucle del astil como el ojo pueden quedar más o menos cerrados.

$$
6 \quad 6 \quad b \quad \&
$$

c: ejecutada por lo general de un solo impulso y de arriba abajo, permitiendo así enlazarse o anexarse con la grafía siguiente. Cuando presenta cedilla, esta suele reducirse a una pequeña coma bajo la $c$, aunque no faltan amplios ligados con otra grafía posterior (no necesariamente la inmediata), bien girando por la izquierda o bien ascendiendo hacia la derecha.

$$
\text { c ce on on a } v \text { a }
$$

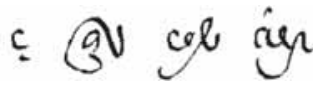

d: es de tipo uncial. Se hace primero el ojo en sentido contrario a las agujas del reloj, y luego el astil, incurvado hacia la izquierda; si ha de enlazar con la siguiente letra, gira a la derecha formando un bucle. Diferente por completo es la $D$ mayúscula que abre el documento, muy afiligranada y de gran módulo.

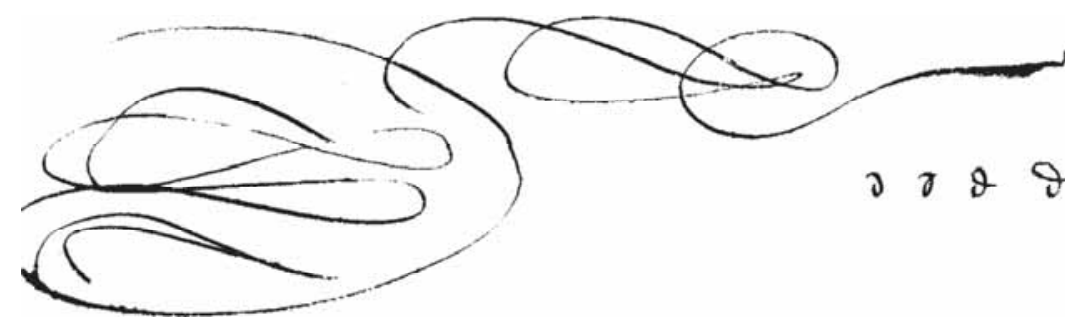

e: hay diferentes modelos pero predomina el uncial. A principio de palabra o como conjunción copulativa, suele adoptar mayor módulo y distinta forma, destacando la de épsilon.

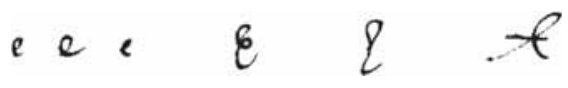


f: aunque conste en ocasiones de dos golpes de pluma, es mucho más frecuente hacerla de una vez.

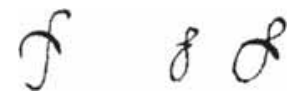

g: ejecutada también de un plumazo, el bucle del caído puede ampliarse. Solo en el vocablo graçia de la primera línea es de diferente tipo.

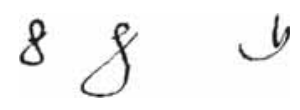

h: a pesar de ser fácilmente reconocible su grafía arquetípica (con un prolongado caído que gira hacia la derecha y vuelve a subir para permitir el enlace con la siguiente letra), se deforma mucho si el trazado se acelera.

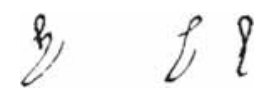

$\mathrm{i}-\mathrm{j}$ : casi siempre lleva punto. Raras veces adopta la hechura de $i$ baja, cuyo caído puede ser más o menos largo; en estos casos puede girar hacia la derecha, como en la $h$, y volver a ascender en busca de la grafía sucesiva. Con valor de $j$, las formas son diversas, aunque siempre semejantes a las de la $i$ baja.

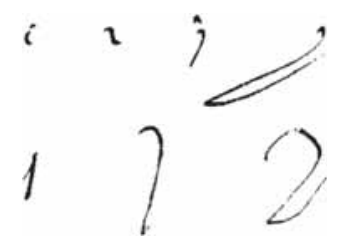

1: por lo general es de tamaño medio, que no sobrepasa la caja del renglón y con bucle en el astil, por lo que tiende a confundirse con la $e$. Eventualmente puede hacerse más alta, y rara vez sin lazo o garabatosa.

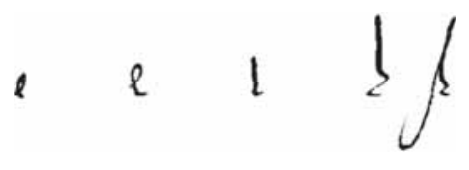


m-n: bien reconocibles; salta alguna con los trazos verticales desenlazados.

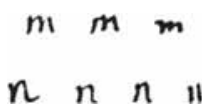

o: puede quedar algo abierta arriba, debido a la cursividad.

\section{$\begin{array}{lllll}0 & 0 & 0 & 0\end{array}$}

p: sus dos tipos más habituales se suelen hacer de una plumada: uno parte del caído, y el otro de la cabeza. Rara vez necesita dos trazos, en cuyo caso la cruza un pie.

$$
20
$$
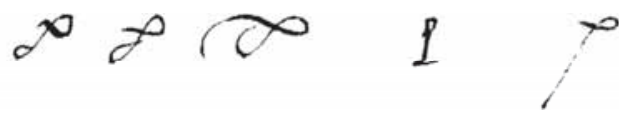

q: presenta otras dos variantes principales. Cuando el caído se acorta, puede hacer un quiebro oblicuo. Esporádicamente surgen formas más cursivas que no cierran la cabeza, o bien el caído las envuelve por la izquierda.

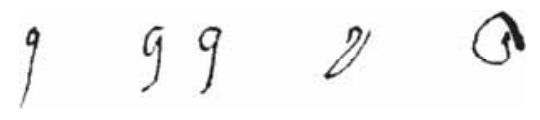

r: generalmente de diseño redondo, en silueta de "dos", que si cierra palabra suele alargar el rasgo final. Si es recta suele circunscribirse a la caja del renglón, a modo de $x$, aunque en el nexo tr puede prolongarse hacia abajo. En cuanto a la mayúscula — sonido /rr/—, se asemeja a una especie de $U$ alta, cortada por un travesaño horizontal que sirve de enlace, pero todo de un plumazo.

$$
=20 x+\text { को कै को }
$$

$\mathrm{s}$ : siempre cursiva, las más corrientes son de doble curva o de espiral, sin que sea extraño ver esta última invertida, con el bucle encima, pudiendo confundirse con una $e$. La $s$ alta se reserva para algunos nexos st.

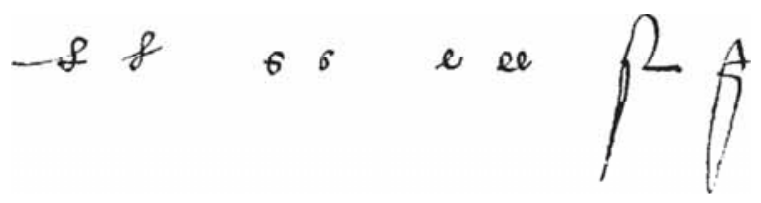


t: semejante a una pequeña cruz griega de dos trazos, sobresaliendo el vertical ligeramente de la caja del renglón. En algunos nexos adquiere la característica forma de tau inclinada hacia la derecha.

$$
+\quad 0
$$

u-v: una u otra pueden representar el mismo sonido y no acomodarse a la fonética actual, siendo corriente encontrarlas alteradas.

$$
u i v>v
$$

x: la única que hay está hecha de un golpe de pluma, prolongando su caído para enlazar con el siguiente grafema.

\section{e}

y: por lo general presenta la horquilla superior, que en las muy cursivas, puede desdibujarse. No es extraño que el caído gire prolongándose hacia la derecha.

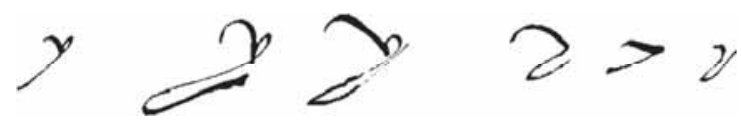

z: adopta forma de "tres". El rasgo final puede voltear a derecha o a izquierda.

$$
3 \xi \xi
$$

Las abundantes abreviaturas suelen construirse por contracción: dha ("dicha"), dhas ("dichas"), dho ("dicho"), dhos ("dichos"), ds ("días"), Flands ("Flandes"), hho ("hecho"), mrs ("maravedíes"), md ("merçed", con la cedilla intercalada), nra ("nuestra"), nro ("nuestro"), susodho ("susodicho") o vros ("vuestros").

\section{Ih oge is iso if feanot of mes m.s ma mo arogho Nzor}


Con mucha frecuencia esta braquigrafía de síncopas se combina con la de letras sobrepuestas: Audi ("Audiencia"), Cast ("Castilla"), dro ("derecho"), $d r^{o} s$ ("derechos"), Gal ("Galicia"), $m^{\text {do }}$ ("mandado"), $m^{o} s$ ("mandamos"), pedim $^{\text {to }}$ ("pedimiento"), pet ${ }^{\text {on }}$ ("petición"), p ("presidente"), primeram ${ }^{t e}$ ("primeramente"), pobeyesemos ("probeyésemos"), pobisiones ("probisiones"), $p u^{c a}$ ("pública"), qui s ("quinientos"), testimi ("testimonio"), tro ("traslado") y Val ("Valencia").

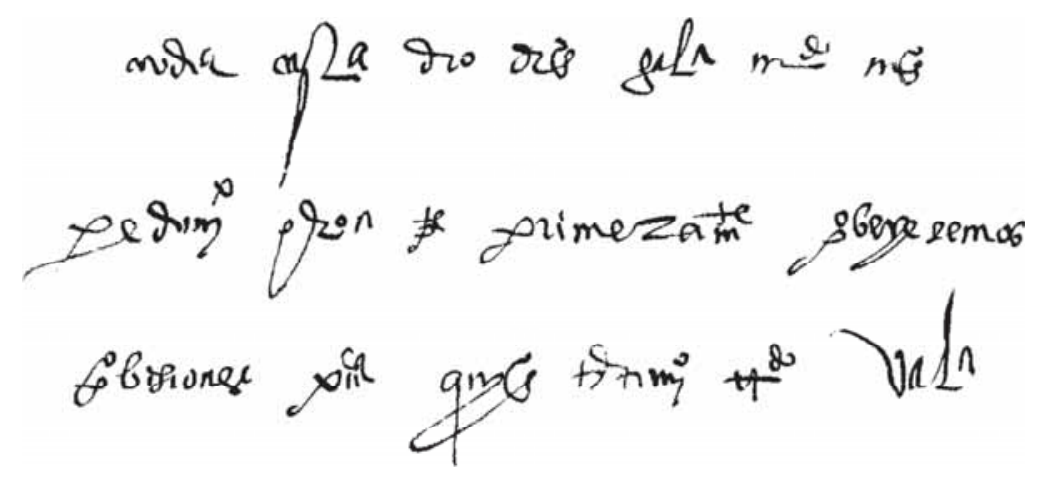

A veces, la misma palabra se contrae de dos formas, como "pleito", abreviado una vez $p^{o}$ y otra $p^{\text {to }}$. Más curioso es el caso de "parte", que siempre se escribe pte pero, mientras que en las cuatro que hay en el texto principal, las tres letras van alineadas, en el brevete del vuelto las dos últimas están sobrepuestas (como en la abreviatura de "presidente" del párrafo anterior).
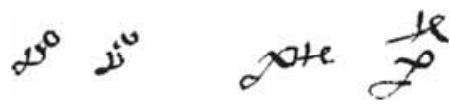

Aunque excepcionalmente, también puede haber letras sobrepuestas en palabras no abreviadas, como "Granada".

\section{sznign}

Apenas se ven signos braquigráficos de carácter general. Si acaso, el trazo corto que corona "anos" o los garabatos para elidir la e en las sílabas des y tes, o en "días".

\section{onir of tiे is}


No se utilizan signos abreviativos de naturaleza específica.

Cabe advertir también que la cruz invocativa cabecera consiste en un largo trazo horizontal cortado por dos verticales breves.

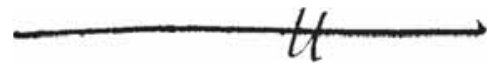

Aparte de la mano principal anónima hay otras en la conscriptio:

- Validaron al dorso con sus firmas y rúbricas los oidores de Granada, licenciados Escipión Antolínez de Burgos, Juan Sarmiento de Valladares y Alonso Núñez de Bohórquez ${ }^{21}$.

- El escribano de la Chancillería Diego de la Fuente quien, además de completar la data añadiendo "quatro" y "jullio", redactó el refrendo.

- Otro amanuense puso en la parte inferior del recto "Es del oficio de Meneses", y en el vuelto añadió "Meneses".

- Distinto oficial anotó las tasas.

- También intervinieron en la validatio el licenciado Juan de Gumiel como registrador y canciller ${ }^{22}$, y un revisor.

\section{ANÁLISIS DIPLOMÁTICO}

El arquetipo de estructura documental ya comentado se refleja puntualmente en la presente provisión, expedida a instancia de la villa de Alcázar de San Juan.

El primer elemento del protocolo es la invocación simbólica de la cruz, que aparece centrada y destacada.

Inicia el texto la intitulación, con el antropónimo regio ("Felipe") tras el "don" del tratamiento de cortesía, seguido de la fórmula divinal "por la graçia de Dios" y la lista de dominios ("rrey de Castilla, de León, de Aragón, de las Dos Çecilias, de Jerusalén, de Navarra, de Granada, de Toledo, de Valencia, de Galicia, de Mallorcas, de Sevilla, de Çerdena (sic), de Córdoba, de Córçega, de Murçia, de Jaén, conde de Flandes y de Tirol, etcétera").

21. A. Vázquez Martínez (1975), 451-469; A. Á. Ruiz Rodríguez (1987), 104-124; E. Soria Mesa (2005), 114-115.

22. Tanto el canciller mayor como el registrador mayor eran dignidades honoríficas; el oficio lo ejercían en la práctica delegados residentes en la Corte y en las chancillerías de Valladolid y Granada. M. S. Martín Postigo (1967), 721-727; A. Á. Ruiz RodríGuez (1987), 138-142; I. Gómez GonzÁlez (1999), 599-616. Sobre Juan de Gumiel en particular pueden encontrarse también referencias en E. Soria Mesa (2005), 135-136. 
Luego, la dirección ("a vos el scribano o scribanos ante quien pasó o en cuyo poder están las scrituras de que en esta nuestra carta se hará minçión, e a cada uno de bos"), y concluye el protocolo la salutación ("salud y graçia").

Incoa el cuerpo en sí la sucinta notificación ("Sepades") que da paso a una amplia exposición que declara la comparecencia del demandante, su requerimiento y petición así como el trámite administrativo seguido ante la Chancillería:

que Pedro de Palomares, procurador en la nuestra Audiencia e de la villa de Alcáçar en el pleito que trata con Pedro de Úbeda y consortes sobre rrazón de çiertas cortas, nos hizo rrelaçión por una petición que en la nuestra Corte y Chanzillería antel presidente e oydores de la nuestra Audiencia questá y rreside en la çiudad de Granada presentó, diziendo que, para presentar en el dicho pleito, su parte tenía neçesidad de un traslado de las probisiones que la dicha villa, su parte, tenía para hazer las dehesas de Villaçentenos y El Açebrón, con las hordenanças que sobre ello avía confirmadas, que nos pedía y suplicaba le mandásemos dar nuestra conpulsoria para que le diésedes un traslado de lo susodicho en pública forma, o que sobre ello le probeyésemos como la nuestra merçed fuese. Lo qual, por los dichos nuestro presidente e oydores visto, fue acordado que debíamos mandar dar esta nuestra carta para bos en la dicha rrazón.

En la disposición, taxativa, Felipe II accede a la solicitud de la villa de Alcázar:

e nos tubímoslo por bien, por la qual bos mandamos que luego que con ella, por parte de la dicha villa, fuéredes rrequerido o rrequeridos, le deys y entreguéys un traslado de las dichas probisiones y hordenanças e confirmaçiones que de suso se a hecho minçión, scrito en linpio, firmado y signado, y en manera que haga fee, para que lo pueda traer y presentar ante los dichos nuestro presidente e oidores para guarda de su derecho, pagandos (sic: pagándoos) vuestros derechos, los quales asentad y firmad al fin dello. Y no dexéys de lo qual ansy hazer y cunplir, constandos (sic: constándoos) primeramente por testimonio signado de scribano que fue çitada y rrequerida la otra parte para ello.

Siguen, como garantía de ejecución, diversas cláusulas sancionativas: prohibitiva ("e no hagades ende al"), penales de pérdida del favor real ("so pena de la nuestra merçed") y pecuniaria ("y de diez mill maravedíes para la nuestra Cámara"), y preceptiva de cumplimiento ("so la qual dicha pena mandamos a qualquier scribano público que para esto fuere llamado, que 
dé al que bos la mostrare testimonio signado con su signo por que nos sepamos cómo se cunple nuestro mandado").

Cierra el cuerpo de la provisión una cláusula corroborativa de haber sido escriturada: "Yo Diego de la Fuente, scrivano del Abdiencia de Su Majestad, la fize scrivir por su mandado, con acuerdo del presidente e oydores de su Rreal Abdiencia".

El escatocolo contiene data y validación. Introduce la primera el participio "Dada" y es tópica ("en Granada") y cronológica: "a quatro días del mes de jullio de mill e quinientos y setenta y tres años".

Cierra todo la validación: sello céreo de placa (solo queda la huella por haberse desprendido) y suscripciones de oidores, chanciller, registrador y otros oficiales de la Chancillería granadina.

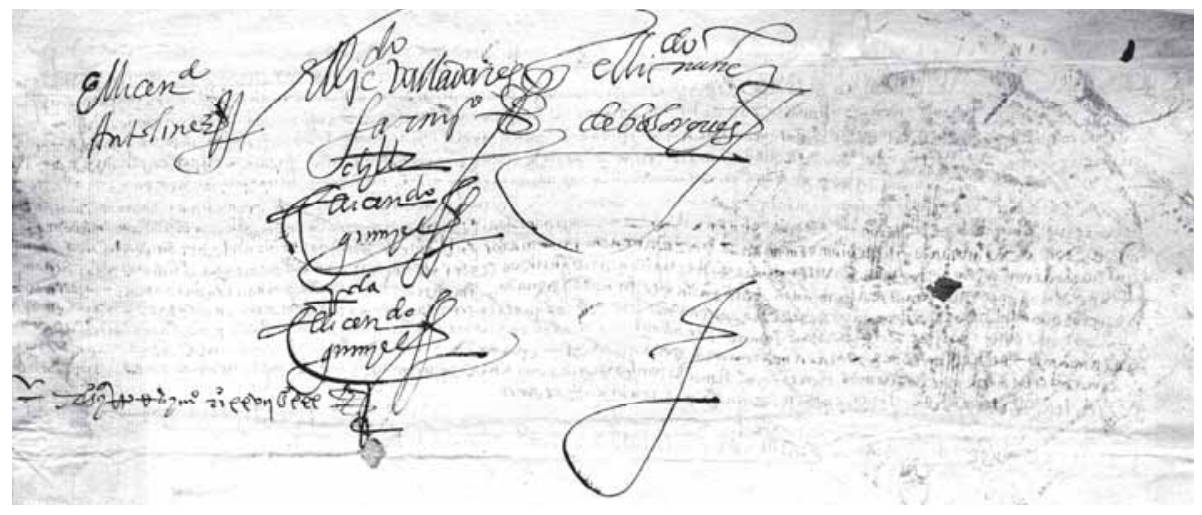

\section{APÉNDICE DOCUMENTAL ${ }^{23}$}

1573, julio, 4. Granada.

Provisión real de Felipe II ordenando al escribano depositario de ciertas escrituras sobre las dehesas de Villacentenos y El Acebrón, sacar un traslado para la villa de Alcázar de San Juan.

Archivo Municipal de Alcázar de San Juan, caja 204, doc. 9. (Cruz).

Don Felipe, por la graçia de Dios rrey de Castilla, de León, de Aragón, de las Dos Çecilias, de Jerusalén, de Navarra, de Granada, de Toledo,

23. La transcripción es paleográfica, es decir, conserva la grafía original de la fuente consultada, salvo uso de mayúsculas y minúsculas, separación y unión de palabras, puntuación y acentuación, sujetas a la ortografía actual. 
de Valencia, de Galicia, / de Mallorcas, de Sevilla, de Çerdena (sic), de Córdoba, de Córçega, de Murçia, de Jaén, conde de Flandes y de Tirol, etcétera, a vos el scribano o scribanos / ante quien pasó o en cuyo poder están las scrituras de que en esta nuestra carta se hará minçión, e a cada uno de bos, salud y graçia. /

Sepades que Pedro de Palomares, procurador en la nuestra Audiencia e de la villa de Alcáçar en el pleito que trata con Pedro de Úbeda y consortes sobre rrazón de / çiertas cortas, nos hizo rrelaçión por una petición que en la nuestra Corte y Chanzillería antel presidente e oydores de la nuestra Audiencia questá y rreside en la çiudad de Granada / presentó, diziendo que, para presentar en el dicho pleito, su parte tenía neçesidad de un traslado de las probisiones que la dicha villa, su parte, tenía para hazer las / dehesas de Villaçentenos y El Açebrón, con las hordenanças que sobre ello avía confirmadas, que nos pedía y suplicaba le mandásemos dar nuestra / conpulsoria para que le diésedes un traslado de lo susodicho en pública forma, o que sobre ello le probeyésemos como la nuestra merçed fuese.

Lo qual, por los dichos nuestro presidente e / oydores visto, fue acordado que debíamos mandar dar esta nuestra carta para bos en la dicha rrazón, e nos tubímoslo por bien, por la qual bos mandamos / que luego que con ella, por parte de la dicha villa, fuéredes rrequerido o rrequeridos, le deys y entreguéys un traslado de las dichas probisiones y hordenanças / e confirmaçiones que de suso se a hecho minçión, scrito en linpio, firmado y signado, y en manera que haga fee, para que lo pueda traer y presentar / ante los dichos nuestro presidente e oidores para guarda de su derecho, pagandos (sic: pagándoos) vuestros derechos, los quales asentad y firmad al fin dello. Y no dexéys de lo qual ansy hazer / y cunplir, constandos (sic: constándoos) primeramente por testimonio signado de scribano que fue çitada y rrequerida la otra parte para ello.

E no hagades ende al so pena / de la nuestra merçed y de diez mill maravedíes para la nuestra Cámara, so la qual dicha pena mandamos a qualquier scribano público que para esto fuere / llamado, que dé al que bos la mostrare testimonio signado con su signo por que nos sepamos cómo se cunple nuestro mandado.

Dada en Granada / a quatro días del mes de jullio de mill e quinientos y setenta y tres años. /

Yo Diego de la Fuente, scrivano del Abdiencia de / Su Majestad, la fize scrivir por su mandado, con acuerdo del presidente e oydores de su Rreal Abdiencia. / 
Es del oficio de Meneses. /

(Al dorso) El licenciado Antolínez (rúbrica). El licenciado Valladares Sarmiento (rúbrica). El licenciado Núñez de Bohorques (rúbrica).

Chanciller, el licenciado Gumiel (rúbrica).

Registrada, el licenciado Gumiel (rúbrica).

(Huella del sello de placa).

Derechos: quatro rreales y medio; rregistro: XXVII; sello: XXX. /

Conpulsoria para sacar scrituras, çitada la parte, a pedimiento de la villa de Alcáçar. /

Corregida (rúbrica).

Meneses.

\section{BIBLIOGRAFÍA}

Aguirre, Domingo de (1769), Descripción histórica del Gran Priorato de San Juan Bautista de Jerusalén en los reinos de Castilla y León, Consuegra. Conservado en la Biblioteca Nacional de España, MSS/20551.

Alces, Antonio de ${ }^{24}$ (2012) "Villacentenos: la menospreciada madre de un pueblo, con las joyas de su arquitectura bajo basura", El Semanal de la Mancha, p. 5.

Arribas Arranz, Filemón (1959), "La carta o provisión real", Cuadernos de la Cátedra de Paleografía y Diplomática, 2, pp. 11-44.

Atienza Santiago, Francisco José (2011), La ermita de San Lorenzo de Alameda de Cervera (notas históricas), Ayuntamiento de Alcázar de San Juan, Alcázar de San Juan.

Atienza Santiago, Francisco José y Mendoza Marín, José Manuel (2011), "Vuelta a empezar: los archivos municipales de Alcázar de San Juan y Daimiel", Arch-e. Revista andaluza de archivos, 4, pp. 269-299.

Atienza Santiago, Francisco José y Sánchez Ruiz, José Fernando (2014), Bibliografía de Alcázar de San Juan, Ayuntamiento de Alcázar de San Juan, Alcázar de San Juan.

Ayala Martínez, Carlos de (ed.) (1995), Libro de privilegios de la orden de San Juan de Jerusalén en Castilla y León (siglos XII-XV): Ms. H211 del Museum and Library of the order of Saint John, de Londres, Editorial Complutense, Madrid.

Barquero GoÑI, Carlos (1997), "La repoblación hospitalaria en la Corona de Castilla (siglos XII-XVI)", Historia, instituciones, documentos, 24, pp. 71-100.

Battelli, Giulio (1954), "Nomenclature des écritures humanistiques", en Nomenclatures des écritures livresques du IX $X^{e}$ au XVI ${ }^{e}$ siècle. Premier Colloque

24. Seudónimo de Antonio Salomón Lizcano. 
international de Paléographie latine, Centre National de la Recherche Scientifique, París, pp. 35-44.

Fairbank, Alfred John y Hunt, Richard William (1993), Humanistic script of the fifteenth and sixteenth centuries, Bodleian Library, Oxford.

Fernández-Montes y Corrales, Luis Miguel (1989), Estudio sobre la carta puebla de Herencia, Ayuntamiento, Herencia.

- (2014), "San Cristóbal, Villacentenos y otras confusiones históricas sobre la ubicación de Herencia", Feria y fiestas de Herencia, Ayuntamiento, Herencia, pp. 82-87.

Galende DíAz, Juan Carlos (1998), "La escritura humanística en la Europa del Renacimiento", Espacio, tiempo y forma. Serie III, Historia Medieval, 11, pp. 187-230.

Gómez González, Inés (1999), "La Chancillería de Granada en el reinado de Felipe II", en E. Belenguer Cebrià (coord.), Felipe II y el Mediterráneo, vol. III, Sociedad Estatal para la Conmemoración de los Centenarios de Felipe II y Carlos V, Madrid, pp. 599-616.

Hernández García, Ángel (2001), "Clasificación diplomática de los documentos reales en la Edad Moderna", Norba, 15, pp. 169-186.

ÍñigueZ Barrena, Francisca (2007), "La verosimilitud, intención de Cervantes en la creación del Quijote", en A. Castro Díaz (ed.), Actas del Congreso Cervantes, el Quijote y Andalucía, Asociación andaluza de profesores de español Elio Antonio de Nebrija, Sevilla, pp. 245-250.

Ligero Móstoles, Ángel (1991-1994), La Mancha de don Quijote, Universidad Popular, Alcázar de San Juan.

López-Menchero Bendicho, Víctor Manuel; Marchante Ortega, Ángel; Esteban Borrajo, Germán y Hervás Herrera, Miguel Ángel (2015), "Piédrola: avance de las intervenciones (2013-2014)", en F. Alía Miranda, J. Anaya Flores, L. Mansilla Plaza y J. Sánchez Lillo (dirs.), I Congreso nacional Ciudad Real y su provincia, vol. III, Instituto de Estudios Manchegos, Ciudad Real, pp. 7-19.

Lorenzo Cadarso, Pedro Luis (2001), El documento real en la época de los Austrias (1516-1700), Universidad de Extremadura, Cáceres.

Mandingorra Llavata, María Luz (1986), La escritura Humanística en Valencia. Su introducción y difusión en el siglo $X V$, Universidad, Valencia.

Martín-Fontecha Guijarro, Ángel y Romero NúÑEz, Jesús (1996), En un lugar de la Mancha: Herencia, Ayuntamiento, Herencia.

Martín Postigo, María Soterraña (1959), La cancillería castellana de los Reyes Católicos, Universidad, Valladolid.

- (1967), "Registrador mayor y chanciller del sello mayor en la segunda mitad del siglo XVI", en Homenaje al excelentísimo señor doctor don Emilio Alarcos García, vol. II, Universidad, Valladolid, pp. 721-731. 
Muñoz Torres, José (2013), Dos ordenanzas del siglo XVI referidas a la conservación de pastos y montes y a la creación del pósito municipal en la villa de Alcázar de San Juan, Ayuntamiento, Alcázar de San Juan.

ReAl Díaz, José Joaquín (1970), Estudio diplomático del documento indiano, Escuela de Estudios Hispanoamericanos, Sevilla.

Rodríguez Domenech, María de los Ángeles (2008), “Aproximación a la cartografía informática del territorio de la orden de San Juan en la provincia de Ciudad Real", Cuadernos de estudios manchegos, 32, pp. 341-367.

Ruiz Albi, Irene (2011), "La escritura humanística documental durante el siglo XVI. El panorama castellano a través de la documentación de Cámara de Castilla (Archivo de Simancas)", en B. CAsado Quintanilla y J. M. López Villalba (coords.), Paleografía III: la escritura gótica (desde la imprenta hasta nuestros días) y la escritura humanística, Universidad Nacional de Educación a Distancia, Madrid, pp. 47-71.

- (2016), "La escritura hispano-humanística moderna", en J. C. Galende DíAz, S. Cabezas Fontanilla y N. Ávila Seonne (coords.), Paleografía y escritura hispánica, Síntesis, Madrid, pp. 217-236.

Ruiz GarcíA, Elisa (1999), "La escritura humanística y los tipos gráficos derivados", en Á. Riesco Terrero (ed.), Introducción a la Paleografía y la Diplomática general, Síntesis, Madrid, pp. 149-176.

Ruiz Rodríguez, Antonio Ángel (1987), La Real Chancillería de Granada en el siglo XVI, Diputación Provincial, Granada.

Sánchez Ruiz, José Fernando y Atienza Santiago, Francisco José (2011), Alcázar en sus documentos hasta finales del siglo XVI, Ayuntamiento, Alcázar de San Juan.

Sanz Fuentes, María José (1981), “Tipología documental de la Baja Edad Media castellana. Documentación real”, en Archivística. Estudios básicos, Diputación Provincial, Sevilla, pp. 237-256.

Serrano De Menchén, Pilar (2015), "Singularidades de una advocación mariana de Gloria: la Virgen de la Encarnación de Peñarroya”, en F. Alía Miranda, J. Anaya Flores, L. Mansilla Plaza y J. Sánchez Lillo (dirs.), I Congreso nacional Ciudad Real y su provincia, vol. II, Instituto de Estudios Manchegos, Ciudad Real, pp. 165-183.

Soria Mesa, Enrique (2005), "Burocracia y conversos. La Real Chancillería de Granada en los siglos XVI y XVII", en F. J. Aranda Pérez (coord.), Letrados, juristas y burócratas en la España moderna, Universidad de Castilla-La Mancha, Cuenca, pp. 107-144.

Tamayo LóPez-Machuca, Alberto (1996), Archivística, Diplomática y sigilografía, Cátedra, Madrid.

- (2012), Historia de la escritura latina e hispánica, Trea, Gijón.

Ullman, Berthold Louis (1960), The origin and development of humanistic script, Edizioni di Storia e Letteratura, Roma. 
VÁzquez Martínez, Alfonso (1975), “Cartas de Felipe II al licenciado Antolínez (1579-1586)", El Museo de Pontevedra, 29, pp. 451-469.

WARDROP, James (1963), The script of humanism: some aspects of humanistic script (1460-1560), Clarendon Press, Oxford.

ZAmponi, Stefano (2004), "La scrittura umanistica", Archiv für Diplomatik, 50, pp. 467-504. 